\title{
Influence Of Each Of The Geometric Errors On The Total Displacement Error Of The Machine
}

\author{
Igor Dimovski, Samoil Samak, Mirjana Trompeska, \\ Martin Hristoski \\ Institute for Advanced Composites and Robotics \\ Prilep, Macedonia \\ igord@iacr.edu.mk, ssamak@iacr.edu.mk. \\ mirjanat@iacr.edu.mk,martinh@iacr.edu.mk
}

\author{
Vladimir Dukovski \\ Faculty of Mechanical Engineering \\ Ss. Cyril and Methodius University \\ Skopje, Macedonia \\ vladimir.dukovski@mf.edu.mk
}

\begin{abstract}
An algorithm for volumetric calibration is developed and verified practically by measuring of all geometric errors after numerical compensation. In this paper, analysis of the contribution of each of 9 translational and 9 rotational position dependent errors and each of 3 position independent errors in total displacement error vector is presented. Changing only one of the errors, and keeping all the others unchanged, the final total error is examined using the simulation based on forward calibration part of the calibration algorithm. The measurement of all 21 volumetric errors is expensive and time consuming. Instead of numerical compensation in the controller, this analysis yields opportunity to enhance accuracy of the machine, measuring and making correction of only few of the geometric errors. Results from the simulation showed that position independent errors have most significant influence on total displacement error. Decreasing of the squareness error $S_{X Y}$ improves the mean of norms of total displacement vectors about $\mathbf{2 5 \%}$, and percentage of improvement for squareness error $S_{\mathrm{ZX}}$ is about $20 \%$. If all squareness errors are reduced by factor 0.04 , then total improvement is more than $51 \%$.
\end{abstract}

Keywords - volumetric calibration; accuracy; geometric errors; compensation

\section{INTRODUCTION}

Metrology is "the science of measurement, embracing both experimental and theoretical determinations at any level of uncertainty in any field of science and technology" - definition given by the International Bureau of Weights and Measures (BIPM) [1], [2]. It is comprehensive and complex science composed of many subfields, but this paper focuses on the subfield applied, technical or industrial metrology, especially the large scale metrology that deals with techniques for accurate 3D measurement and compensation of an industrial objects with dimensions larger then few meters [3].

The Automated Fiber Placement (AFP) and Automated Tape Layup (ATL) technologies are used for production of a structures or parts by placing/laying fibers/tapes of a composite material. Their products are with large dimensions, that fit in the large scale metrology. The accuracy in those two technologies is very important, because even very small irregularity in the position or orientation of AFP/ATL head can cause gaps between the tapes, overlaps of the tapes, folds in the laminate, delamination of the layups and other defects of the final product [4]. Therefore, it's recommended to ensure that the AFP/ATL machine will achieve maximal accuracy during the production process, by applying calibration, a procedure of measuring the machine errors and their compensation.
The robotized machine may have a two types of errors nongeometric and geometric caused by the machine geometry, which influence will be considered in this paper. According to Elatta et al. [5], all non-geometrical errors are responsible for about $10 \%$ of the total error. Details about categories of error sources - kinematic and non-kinematic (dynamics and structure), as well as some classification of the calibration procedures may be found in [6], [7] and [8].

According to ISO230-1:2012 [9] and ISO 230-2:2014 [10] standards and the ISO technical report [11], in total 21 geometrical errors exist for a machine with 3 degrees of freedom (DOF). All 21 errors are detailed in [12], as well as the description of forward calibration algorithm used for simulation in this paper. They are shown on Fig. 1.

Mathematical model for optimization in determination of interpolation polynomial coefficients is based on the approach described in [8]. Total displacement error at knots of the workspace cells is calculated regarding the measured or interpolated values of the volumetric errors and the kinematic chain, using approach detailed in [13].

In the literature, there are several calibration methods that have a different ways of measuring of the geometric errors or different ways of their compensation. In the traditional ones, each geometric error of each axis is measured separately, and then the compensation is also performed separately for each axis. In the traditional methods the dependence of kinematic configuration has small or no influence. Opposite, in the contemporary methods the dependence of the kinematic configuration has significant influence because all 21 geometric errors, for all axes, could be determined by only one measurement procedure [14], [15], [16].

Comprehensive calibration procedure was developed for numerical compensation of all 21 geometric errors of AFP/ATL machine, which comprise of two algorithms for forward and inverse calibration. After the implementation of this calibration procedure detailed in [12] and [17], the accuracy of the machine is improved by $90 \%$, verifying the correctness of the used algorithms.

For applying this kind of numerical calibration, first all the 21 geometric errors must be estimated, performing measurement procedure, which is very time consuming. For reducing the measuring time, as an alternative, there can be measured and compensated only those geometric errors that have the greatest contribution in the total displacement error vector. In this paper, an analysis of the influence of each 


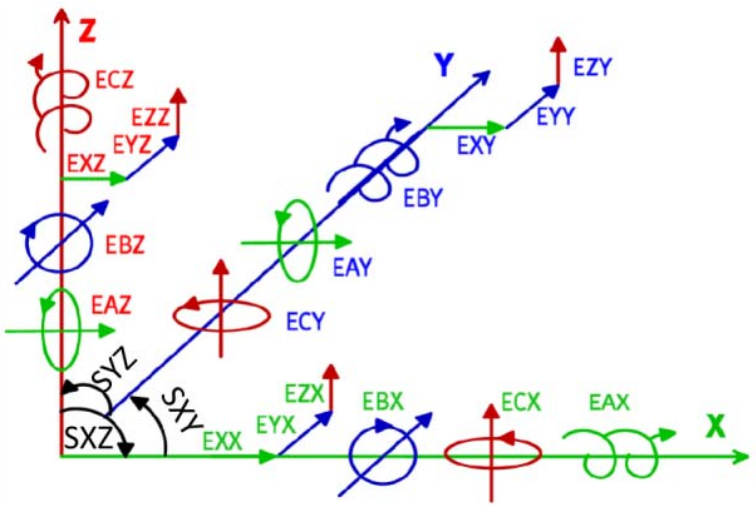

Fig. 1. 21 volumetric errors for 3 linear axes

geometric error in the total displacement error of the machine is presented. The literature lacks of this kind of analysis.

\section{Methodology}

\section{A. Numerical compensation algorithm}

Ideally, all 21 measured geometric errors should be numerically compensated. Some of the controllers have the ability to make compensation of all 21 errors, reading the error map obtained after comprehensive measurement procedure. Most of controllers, use lookup tables and have the ability to compensate only few of the errors.

We have developed and implemented comprehensive volumetric calibration procedure for 3 linear axes. Original algorithm for numerical compensation is developed as a part of such procedure.

In order to verify this algorithm, two measurements were performed on the linear axes of large workspace ATL machine, produced by Mikrosam company. The measurement equipment and appropriate software from Etalon AG company was used. Both measurements were done during September 2016.

The workspace of the ATL machine was $12 \times 2 \times 1.5$ meters. The measurement step of $250 \mathrm{~mm}$ for each axis was chosen and appropriate interpolation step of $25 \mathrm{~mm}$.

The measurement strategy was built in order to reduce all the uncertainties below $2 \mu \mathrm{m}$. According to this strategy, 9 different paths were planned, with total of 3149 measuring positions, across the machine volume. These 9 paths are combined with 4 different position of the laser interferometer and different combinations of offsets.

The same strategy is applied in both measurements - before and after compensation. After the first measurement, collected data were used as input in our calibration algorithm. Large amount of data was used to perform the forward calibration procedure and to build interpolation polynomials for total displacement error estimation for all cells of the workspace's grid. Inverse calibration procedure was performed in real time, so in the second measurement, all measured positions were reached along compensated positions path, taking estimated total displacement error into consideration.

Measuring procedure is time consuming. Both performed measurement and data collecting took around 10 hours each. After the second measurement, obtained error values for all geometric errors, especially the total displacement error verified the correctness of the implemented volumetric calibration procedure.

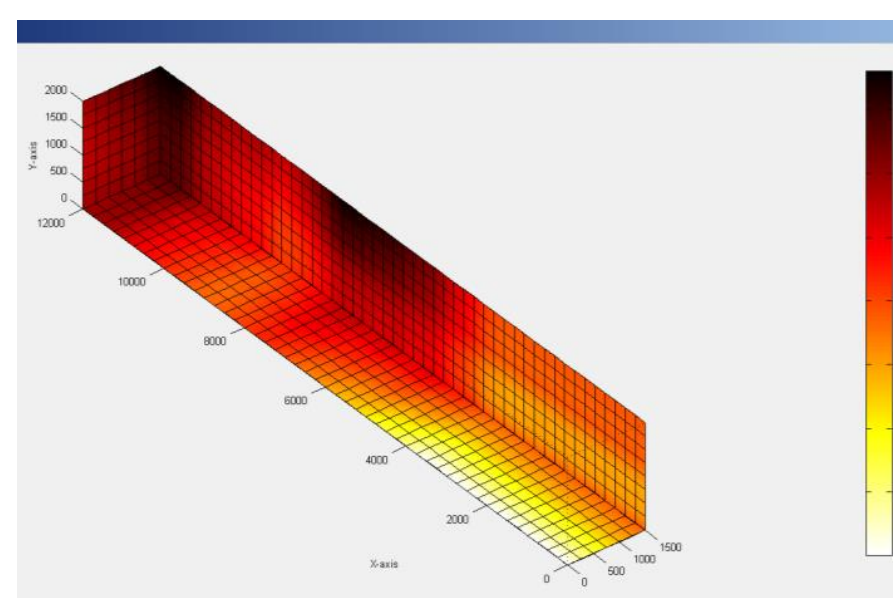

Fig. 2. Total displacement error - uncompensated

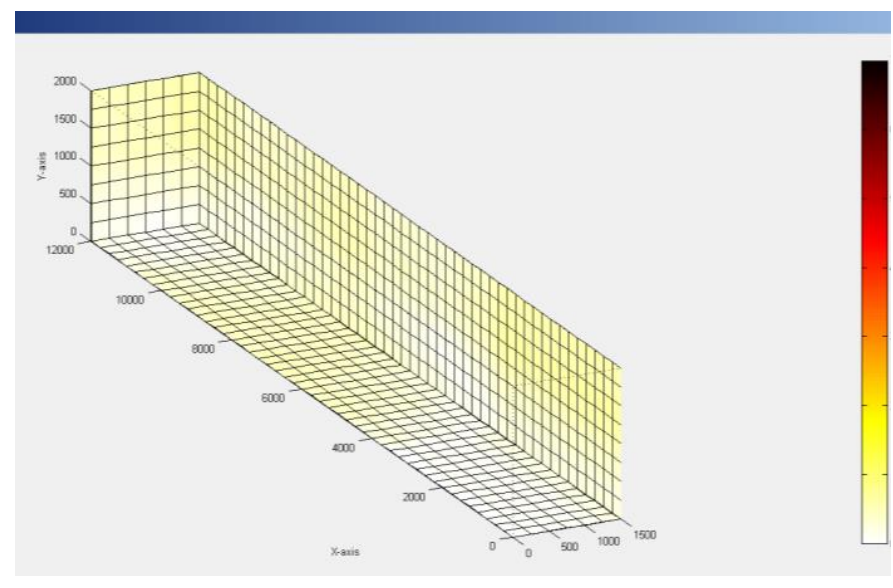

Fig. 3. Total displacement error -compensated

Numerical compensation algorithm resulted with more than $90 \%$ improvement of the accuracy of the tested machine, as it could be seen at Fig. 2. (before calibration) and Fig. 3. (after calibration).

\section{B. Simulation and analysis}

Since the measurement procedure is expensive and time consuming, alternative methods for enhancing machine's accuracy should be developed.

Ideally, all 21 geometric errors should be taken into consideration and comprehensive volumetric calibration procedure should be applied in order to enhance accuracy of the machine. Alternatively, only some of these errors could be measured and corrected. Contribution of each of the geometric errors in the total displacement error should be analyzed.

The same numerical compensation algorithm is used to simulate situation where all Position Dependent Geometric Errors (PDGE) are uniformly distributed along the axes and Position Independent Geometric Errors (PIGE) are all the same. Next, it is assumed only one of the errors is reduced and total displacement error changes are analyzed.

All 9 PDGE translational errors are assumed to be equal to $50 \mu \mathrm{m}$ in every measurement point along the appropriate axis. All 9 PDGE rotational errors are assumed to be equal to $50 \mu \mathrm{rad}$ in every measurement point along the appropriate axis. Along $\mathrm{X}$ axis 35 measurement point are taken, along $\mathrm{Y}$ axis, there are 9 , and along the $Z$ axis, there are 7 measurement points. That 
way, machine's workspace is divided to 1632 grid cells with total of 2205 knots.

PIGE, or squareness errors are taken to be all equal to $20 \mu \mathrm{rad}$.

The actual coordinates $\mathbf{P}_{\text {act }}$ of the grid knots are calculated using approach explained in details in [12]. Difference between the actual, and the nominal coordinates $\mathbf{P}_{\text {nom }}$ of the grid knots yields the total displacement error vector:

$$
\mathbf{E}=\mathbf{P}_{\text {act }}-\mathbf{P}_{\text {nom }}
$$

The norm of 2205 total displacement error vectors is analyzed. According to kinematic chain of the linear axes of the tested machine:

$$
\mathrm{X} \rightarrow \mathrm{Y} \rightarrow \mathrm{Z}
$$

the sequence of norms of total displacement vectors has mean of $609.4 \mu \mathrm{m}$, with standard deviation of $174.2 \mu \mathrm{m}$.

One by one, every type of geometric errors is replaced by smaller one, all the coefficients and actual coordinates are recalculated and the appropriate new total displacement error vectors are obtained, simulating forward calibration procedure for the knots, while all other errors are kept unchanged. Only mean of the norms of these vectors and their standard deviations are analyzed. Reduction factor for PDGE's is taken to be 0.01 , and for squareness errors, reduction factor is taken to be 0.04 . These factors are comparable with real measurement data, obtained after compensation, in the second measurement.

\section{RESULTS AND DISCUSSION}

In order to determine contribution of each error in the total displacement error, simulation is made and the results are summarized in the Table I.

Evidently, position independent errors have most significant influence on total displacement error. Decreasing of the squareness error $\mathrm{S}_{\mathrm{XY}}$ improves the mean of norms of total displacement vectors about $25 \%$, and percentage of improvement for squareness error $\mathrm{S}_{\mathrm{ZX}}$ is about $20 \%$. If all squareness errors are reduced by factor 0.04 , then total improvement is more than $51 \%$.

Comparing the mean of the norms of total displacement vectors for all knots to the appropriate mean of $609.4 \mu \mathrm{m}$ with uniformly distributed, predicted theoretical errors before decreasing of the specified error, is shown in Table II (differences are expressed in percentage).

The axis $\mathrm{X}$ is longest, and it is lead axis in the kinematic chain (2). Probably, that is the reason why positional error $\operatorname{EXX}(\mathrm{x})$ and straightness errors $\operatorname{EXY}(\mathrm{y})$ and $\operatorname{EXZ}(\mathrm{z})$ have greatest contribution in total displacement error, from all position dependent errors. Their improvement percentage is about $7 \%$.

All other errors have smaller contribution in total error. One can conclude translational errors are more significant compared to rotational errors.

The influence of the most significant errors on the total errors is depicted on Fig. 4.
TABLE I SIMULATION RESULTS SUMMARY

\begin{tabular}{|l|l|c|c|}
\hline \multirow{2}{*}{} & \multicolumn{3}{|c|}{ Decreased error and norm of total displacement vector } \\
\cline { 2 - 4 } & \multicolumn{1}{|c|}{ Geometric error type } & Mean $(\boldsymbol{\mu m})$ & St. dev $(\boldsymbol{\mu m})$ \\
\hline 1 & All PIGE's & 297.5 & 23.7 \\
\hline 3 & $\mathrm{~S}_{\mathrm{XY}}$ & 459.2 & 131.2 \\
\hline 4 & $\mathrm{~S}_{\mathrm{XZ}}$ & 489.5 & 109.8 \\
\hline 5 & $\mathrm{E}_{\mathrm{XX}}(\mathrm{x}), \mathrm{E}_{\mathrm{XY}}(\mathrm{y}), \mathrm{E}_{\mathrm{XZ}}(\mathrm{z})$ & 568.3 & 170.7 \\
\hline 6 & $\mathrm{~S}_{\mathrm{YZ}}$ & 575.2 & 162.3 \\
\hline 7 & $\mathrm{E}_{\mathrm{YX}}(\mathrm{x}), \mathrm{E}_{\mathrm{BY}}(\mathrm{y})$ & 577.1 & 155.4 \\
\hline 8 & $\mathrm{E}_{\mathrm{YY}}(\mathrm{y}), \mathrm{E}_{\mathrm{YZ}}(\mathrm{z}), \mathrm{E}_{\mathrm{ZY}}(\mathrm{y}), \mathrm{E}_{\mathrm{ZZ}}(\mathrm{z})$ & 592.4 & 175.9 \\
\hline 9 & $\mathrm{E}_{\mathrm{CY}}(\mathrm{y}), \mathrm{E}_{\mathrm{AZ}}(\mathrm{z}), \mathrm{E}_{\mathrm{BZ}}(\mathrm{z}), \mathrm{E}_{\mathrm{CZ}}(\mathrm{z})$ & 594.0 & 177.6 \\
\hline 10 & $\mathrm{E}_{\mathrm{AX}}(\mathrm{x})$ & 609.4 & 174.2 \\
\hline 11 & $\mathrm{E}_{\mathrm{AY}}(\mathrm{y})$ & 624.4 & 180.6 \\
\hline 12 & $\mathrm{E}_{\mathrm{CX}}(\mathrm{x})$ & 652.9 & 192.4 \\
\hline
\end{tabular}

TABLE II. PERCENTAGE OF IMPROVEMENT AFTER DECREASING OF

\begin{tabular}{|c|c|c|}
\hline & \multicolumn{2}{|c|}{$\begin{array}{c}\text { Mean of norms of total displacement errors } \\
\text { before decreasing: } 609.4 \mu \mathrm{m}\end{array}$} \\
\hline & Geometric error type & $\begin{array}{l}\text { Percentage of } \\
\text { improvement }\end{array}$ \\
\hline 1 & All PIGE's & $51.2 \%$ \\
\hline 2 & $\mathrm{~S}_{\mathrm{XY}}$ & $24.6 \%$ \\
\hline 3 & $\mathrm{~S}_{\mathrm{XZ}}$ & $19.7 \%$ \\
\hline 4 & $\mathrm{E}_{\mathrm{XX}}(\mathrm{x}), \mathrm{E}_{\mathrm{XY}}(\mathrm{y}), \mathrm{E}_{\mathrm{XZ}}(\mathrm{z})$ & $6.7 \%$ \\
\hline 5 & $\mathrm{~S}_{\mathrm{YZ}}$ & $5.6 \%$ \\
\hline 6 & $\mathrm{E}_{\mathrm{BX}}(\mathrm{x}), \mathrm{E}_{\mathrm{BY}}(\mathrm{y})$ & $5.3 \%$ \\
\hline 7 & $\mathrm{E}_{\mathrm{YX}}(\mathrm{x}), \mathrm{E}_{\mathrm{YY}}(\mathrm{y}), \mathrm{E}_{\mathrm{YZ}}(\mathrm{z})$ & $2.8 \%$ \\
\hline 8 & $\mathrm{E}_{\mathrm{ZX}}(\mathrm{x}), \mathrm{E}_{\mathrm{ZY}}(\mathrm{y}), \mathrm{E}_{\mathrm{ZZ}}(\mathrm{z})$ & $2.5 \%$ \\
\hline 9 & $\mathrm{E}_{\mathrm{CY}}(\mathrm{y}), \mathrm{E}_{\mathrm{AZ}}(\mathrm{z}), \mathrm{E}_{\mathrm{BZ}}(\mathrm{z}), \mathrm{E}_{\mathrm{CZ}}(\mathrm{z})$ & $0 \%$ \\
\hline 10 & $\mathrm{E}_{\mathrm{AX}}(\mathrm{x})$ & $-0.1 \%$ \\
\hline 11 & $\mathrm{E}_{\mathrm{AY}}(\mathrm{y})$ & $-2.5 \%$ \\
\hline 12 & $\mathrm{E}_{\mathrm{CX}}(\mathrm{x})$ & $-7.1 \%$ \\
\hline
\end{tabular}
SPECIFIED ERROR(S)

Because of the kinematic chain, the rotational errors $\operatorname{ECY}(y), \operatorname{EAZ}(z), \operatorname{EBZ}(z), \operatorname{ECZ}(z)$ have no contribution at all. Surprisingly, decreasing of the geometric errors $\operatorname{EAX}(\mathrm{x})$, $\operatorname{EAY}(y)$ and $\operatorname{ECX}(x)$, led to greater total error. That means, theoretical model of keeping position dependent errors constant along the axis, together with complexity of common connections between the geometric errors should be changed, and some other error distributions should be analyzed in the future work.

Real data from measurement before and after compensation illustrates the distribution of position dependent error $E_{Z Y}(y)$ along the Y-axis. As Fig. 5 shows, the absolute values are decreased, but the sign is changed. 




Fig. 4. Contribution of the most significant geometric errors on the norm of total displacement vector

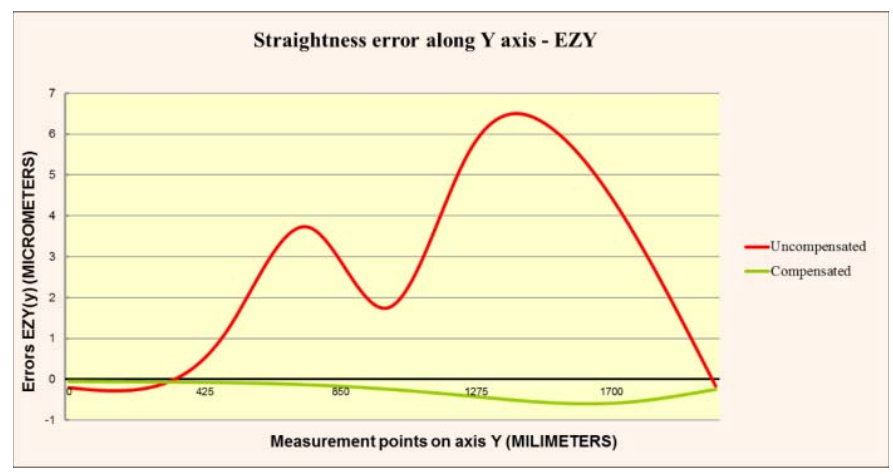

Fig. 5. Real data distribution

\section{CONCLUSION}

In this paper, the influence of each of the geometric errors on the accuracy of the tool position of computerized machines ( $\mathrm{CNC}$ machines and robots) is explored. That is important due to the fact that measurement procedure for estimation of all in total 21 volumetric errors, according to appropriated ISO standard is extensive and expensive, time consuming process, and online software compensation could additionally increase complexity of the entire system. Disclosure specified errors have dominant contribution, allows suggestions to make physical intervention in the machines construction and assembling. Accuracy of the machine should be enhanced that way, and moreover, the number of measurements, or measurement points could be reduced. Results of the simulation and analysis have confirmed our expectations.

\section{REFERENCES}

[1] E. Perotto, R. Canziani, R. Marchesi, P. Butelli, "Environmental performance, indicators and measurement uncertainty in EMS context: a case study". Journal of Cleaner Production, 16(4), 2008, pp. 517-530.

[2] JCGM, "200: 2012 International vocabulary of metrology-Basic and general concepts and associated terms (VIM). 3rd (2008 version with minor corrections).", JCGM, 2012.

[3] S. Kyle, "Large scale metrology", Handbook of measuring system design. Vol. 3. Wiley, 2005, pp.1287-1303

[4] A. Jordaens, T Steensels, "Formation of defects in flat laminates during automatic tape laying" (framework of a master's thesis), Faculty of engineering technology, Leuven, Belgium, 2015

[5] A.Y. Elatta, L. Pei Gen, F.L. Zhi, Y. Daoyuan, L. Fei, "An overview of Robotic Calibration", Information Technology Journal 3(1), ISBN 1682 602, 2004, pp. 74-78

[6] A. Joubair, A. Nubiola, I. Bonev, "Calibration Efficiency Analysis Based on Five Observability Indices and Two Calibration Models for a Six-Axis Industrial Robot" SAE Int. J. Aerosp. 6(1):2013, doi:10.4271/2013-01-2117, 2013

[7] L.K. Conrad., P.S. Shiakolas, T.C. Yih, "Robotic calibration issues: Accuracy, Repeatability and Calibration", Proceedings of the 8th Mediterranean Conference on Control \& Automation (MED 2000), Rio, Patras, Greece, 2000

[8] B.W.Mooring, Z.S.Roth, M.R.Driels, "Fundamentals of manipulator calibration", John Wiley \&Sons Inc., 1991

[9] ISO 230-1:2012 "Test code for machine tools -- Part 1: Geometric accuracy of machines operating under no-load or quasi-static conditions", an International Standard, by International Standards Organization, 2012

[10] ISO 230-2:2014 “Test code for machine tools - Part 2: Determination of accuracy and repeatability of positioning of numerically controlled axes", an International Standard, by International Standards Organization, 2014

[11] Techical report: Machine tools - numerical compensation of geometric errors, ISO/TR 16907:2015, ISO, 2015

[12] S. Samak, I. Dimovski, V. Dukovski, M. Trompeska, "Volumetric calibration for improving accuracy of AFP/ATL machines", $7^{\text {th }}$ International scientific conference of defensive technologies, OTEH 2016 Proceedings, ISNB 978-86-81123-82-9, 2016, pp. 727-732

[13] G. Ren, J. Yang, G. Liotto, C. Wang, "Theoretical Derivations of 4 body Diagonal Displacement Errors in 4 Machine Configurations", Proceedings of the LAMDAMAP Conference, Cransfield, UK, 2005

[14] K.A. Jeffries, "Enhanced Robotic Automated Fiber Placement with Accurate Robot Technology and Modular Fiber Placement Head", SAE Int. J. Aerosp. 6(2):2013, doi:10.4271/2013-01-2290, 2013

[15] R. Flynn, T. Rudberg, J. Stamen, “Automated Fiber Placement Machine Developments: Modular Heads, Tool Point Programming and Volumetric Compensation", SME Technical Paper, 2011

[16] B. Saund, R. DeVlieg, "High Accuracy Articulated Robots with CNC Control Systems" SAE Int. J. Aerosp. 6(2):2013, doi:10.4271/2013-012292, 2013

[17] I. Dimovski, S. Samak, M. Trompeska, V. Dukovski. "Avoiding heavy computations in inverse calibration procedure for 7 DOF robot manipulator", Journal of Electrical Engineering and Information Technologies - JEEIT, 1.1-2: 2016, pp. 37-43 